RESEARCH PAPER

\title{
Prevalence and correlates of internet cigarette purchasing among adult smokers in New Jersey
}

\author{
M Hrywna, C D Delnevo, D Staniewska
}

Tobacco Control 2004;13:296-300. doi: 10.1136/tc.2003.006783

See end of article for authors' affiliations

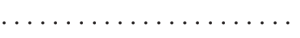

Correspondence to: Mary Hrywna, 335

George Street, Suite 2200,

New Brunswick, NJ 08903, USA;

hrywnama@umdni.edu

Received

19 November 2003

Accepted 27 April 2004
Objective: To examine the prevalence and correlates of internet cigarette purchasing among adult smokers.

Design: Analysis of internet purchasing in data from a population based telephone survey of New Jersey households. Logistic regression was used to determine factors associated with internet cigarette purchasing, adjusting for year, demographic, and smoking behaviour variables.

Participants: 3447 current cigarette smokers pooled from three cross sectional surveys conducted in 2000, 2001 , and 2002.

Main outcome measures: Ever purchasing tobacco and usually buying cigarettes via the internet.

Results: Among all current cigarette smokers, ever having purchased tobacco via the internet increased from $1.1 \%$ in 2000 to $6.7 \%$ in 2002 and usually buying cigarettes via the internet increased from $0.8 \%$ in 2000 to $3.1 \%$ in 2002. Among current cigarette smokers with internet access, ever having purchased tobacco via the internet was higher among those who reported smoking 31 or more cigarettes per day (adjusted odds ratio (OR) 3.9, 95\% confidence interval (CI) 1.5 to 10.2) and those without a past year quit attempt (adjusted $\mathrm{OR} 1.8,95 \% \mathrm{Cl} 1.1$ to 3.0). Usually purchasing cigarettes via the internet was higher among those aged $45-64$ years (adjusted $\mathrm{OR} 4.4,95 \% \mathrm{Cl} 1.1$ to 17.1) and who reported having their first cigarette $\leqslant 30$ minutes after waking (adjusted OR $3.3,95 \% \mathrm{Cl} 1.2$ to 9.2 ).

Conclusions: Although higher prices are known to reduce the demand for cigarettes, internet cigarette purchasing is likely to weaken this effect, particularly among heavy, more dependent smokers who are less interested in quitting.
"The ideal product to sell online would be easy to pack and ship, be much cheaper than what's charged at the retail counter, and be craved by tens of millions of people every day. ${ }^{\prime \prime}$

( $\mathrm{n}$ the face of it, cigarettes appear to be an ideal product to distribute via the internet, and the steady growth of internet vendors indicates that this new market for cigarette sales in the USA is thriving and expanding. Ribisl and colleagues identified 88 US based websites selling cigarettes between November 1999 and January $2000 .^{2}$ A follow up study two years later identified 195 cigarette vendors. ${ }^{3}$ Others suggest there are currently anywhere from 400-600 US and foreign based websites selling cigarettes. ${ }^{45}$ One expert predicted that internet cigarette sales would account for $14 \%$ of the total US market by 2005 or roughly $\$ 5$ billion in sales. ${ }^{6}$ A more recent estimate is that $2 \%$ of all cigarettes purchased in fiscal year 2003 were purchased online.

The issue of internet cigarette purchasing is particularly timely given recent increases in cigarette excise taxes. A total of 31 states, the District of Columbia, and Puerto Rico implemented tax increases in 2002 and 2003, including five states that instituted consecutive tax increases during these two years. ${ }^{8}$ On 1 July 2002, New Jersey imposed a 70 cent increase in the cigarette excise tax, bringing the per pack tax to $\$ 1.50$, one of the highest tobacco taxes in the nation at that time. The state raised its cigarette excise tax again to $\$ 2.05$ on 1 July 2003 and to $\$ 2.40$ on 1 July 2004, increasing the cigarette excise tax for the third time in as many years.

Internet vendors often promote their cigarettes as tax-free, advertising them below retail prices. ${ }^{2}$ For example, a study conducted in January 2002 found the median online price for a carton of Marlboro cigarettes was \$28.99 and \$21.25 for duty-free Marlboro, including advertised shipping costs. ${ }^{9}$ Hodge and colleagues found that cartons sold on American Indian owned internet websites ranged from \$26 to \$37 during 2002, and the purchase of several cartons typically provided free same day shipping. ${ }^{10}$ The retail price in 2003 for premium brand cigarettes was roughly $\$ 46-48$ per carton at gas stations and convenience stores in central New Jersey, with the applicable state excise and sales taxes alone totalling more than \$27 per carton.

The federal Jenkins Act requires any person who sells and ships cigarettes across a state line to a buyer other than a licensed distributor to report the sale to the buyer's state tobacco tax administrator. ${ }^{11}$ However, the majority of internet cigarette vendors claim that they do not comply with this law, often maintaining that they will not report cigarette sales to out-of-state tax collection officials. ${ }^{2}{ }^{12}$ If an internet cigarette vendor does not add the applicable state excise tax to the purchase nor report cigarette sales to states, then the burden of tax reporting and payment falls on the buyer. So while buyers are often not charged the excise tax by internet vendors when purchasing cigarettes, they are legally responsible for remitting it to their home state. This way internet cigarette vendors are able to keep cigarette prices low while states lose millions of dollars in tax revenue from these sales.

Despite the documented growth of internet cigarette vendors, little is actually known about cigarette purchasing via the internet. The existing literature on internet cigarette purchasing addresses the characteristics of internet vendors, ${ }^{2}$ vendor compliance with sales to minors, ${ }^{13-15}$ and internet cigarette purchasing by youth. ${ }^{16}{ }^{17}$ While internet vendors undoubtedly present a challenge to restricting youth access to cigarettes, adults are the legal market for online sales and 
clearly the most likely to be engaging in this practice. There is only one published study that has examined adult internet cigarette purchasing. In 1999, Emery and colleagues ${ }^{18}$ found that $0.3 \%$ of smokers in California avoided the state excise tax by usually purchasing cigarettes over the internet. Additionally, work presented by Hyland et al ${ }^{19}$ found that almost 5\% of smokers in four New York State communities, where the state cigarette excise tax was the highest in the nation at the time of their study in 2001, reported regularly purchasing cigarettes via the internet.

Since these studies were conducted, there has been a proliferation of internet cigarette vendors and over two thirds of US states have increased their cigarette excise taxes. Moreover, no published study, to our knowledge, has ever identified factors associated with internet cigarette purchasing by adult smokers. The present study describes the prevalence of internet cigarette purchasing among adult cigarette smokers in New Jersey over a three year period and identifies factors associated with ever and usually purchasing cigarettes via the internet.

\section{METHODS}

\section{Data source}

We examined data from the New Jersey Adult Tobacco Survey (NJATS), a point-in-time survey to monitor tobacco use behaviour, knowledge, and attitudes. The institutional review boards of the University of Medicine and Dentistry of New Jersey and the New Jersey Department of Health and Senior Services approved the study. The NJATS utilises a random-digit-dial (RDD) telephone survey designed to oversample certain subgroups of interest to yield approximately 1000 young adults (aged 18-24 years), 1000 current smokers, 500 recent quitters, and 1000 non-smokers. Overall response rates were calculated by multiplying the screening response rate by the extended interview cooperation rate. Overall response rates were $46.2 \%$ for adults in 2000 ( $\mathrm{n}=3605)$, $39.5 \%$ in 2001 ( $\mathrm{n}=3930)$, and $15.8 \%$ in $2002(\mathrm{n}=4004)$. Data from the three years of NJATS were pooled to increase statistical power.

\section{Inclusion criteria and measures}

Our analysis focused on determining the prevalence and characteristics associated with internet cigarette purchasing. To determine overall prevalence of ever and usual internet purchasing, we included all current cigarette smokers. Current cigarette smoking was defined as having ever smoked 100 cigarettes in a lifetime and currently smoking on some days or every day. The 2000, 2001, and 2002 NJATS included a total of 3447 current cigarette smokers. We examined two items related to internet cigarette purchasing, ever purchased and usually purchase. Ever purchased was assessed by asking, "Have you ever purchased tobacco products on the internet?". Usual purchase was assessed by asking, "Do you usually buy your cigarettes in New Jersey, out of state, or over the internet?".

To identify characteristics associated with internet cigarette purchasing, we excluded current cigarette smokers without internet access $(\mathrm{n}=1048)$. In 2000 and 2001, survey participants were asked, "Do you have access to the internet at home, school, or work?". In 2002, participants were asked, "Have you ever used the internet?". Overall rates of internet access among survey participants were similar across years, $70.6 \%, 70.6 \%$, and $69.5 \%$ (unweighted), respectively. We then performed multivariate analyses on the 2399 current cigarette smokers with internet access. Internet cigarette purchasing was examined by eight characteristics: year of survey, age, race, sex, level of education, cigarettes smoked per day, time to first cigarette of the morning, and the occurrence of a quit attempt in the past year.

\section{Statistical analysis}

Sample weights were applied to adjust for non-response and the varying probabilities of selection, including those resulting from oversampling. The data were also weighted for age, race, and sex to match the demographics of adults in New Jersey as characterised by the 2000 US Census. SUDAAN statistical software, which corrects for the complex sample design, was used to generate $95 \%$ confidence intervals (CI). ${ }^{20}$ Differences between estimates were considered significant at the $\mathrm{p}=0.05$ level if the $95 \%$ CI did not overlap. A multivariate logistic regression was used to assess the independent association of the factors predictive of ever and usually purchasing via the internet among adult current cigarette smokers. Adjusted odds ratio (OR) and their 95\% CI are presented.

\section{RESULTS}

Table 1 presents the characteristics of all cigarette smokers and those with access to the internet. Compared with all smokers, smokers who accessed the internet were younger, more likely to be white, and more likely to have greater than a high school education. Additionally, smokers who accessed the internet reported smoking fewer cigarettes per day.

The overall percentage of ever purchasing tobacco via the internet among all current cigarette smokers was $2.9 \%$ (table 2). From 2000 to 2002, the percentage of current smokers who reported ever purchasing tobacco via the internet significantly increased from $1.1 \%$ to $6.7 \%$, an increase of $509 \%$. Additionally, all current cigarette smokers were asked where they usually bought their cigarettes. Overall, $1.3 \%$ of smokers reported usually buying their cigarettes via the internet. The percentage of smokers who reported internet as their usual source of cigarettes significantly increased from $0.8 \%$ in 2000 to $3.1 \%$ in 2002, an increase of $288 \%$. Rates of cigarette internet purchasing among current smokers with internet access are also provided in table 2 .

Table 3 presents the prevalence and adjusted odds ratio of ever purchasing tobacco via the internet among current smokers with internet access by demographic characteristics and tobacco use behaviour. There were significant differences in the proportion of smokers who ever purchased tobacco via the internet by race, age, and time to first cigarette, but after adjusting for all other variables, these differences were no longer significant. However, current cigarette smokers who reported smoking 31 or more cigarettes per day had a greater likelihood of ever purchasing tobacco via the internet than smokers who reported 10 or fewer cigarettes per day. Also, smokers who did not make a serious quit attempt in the past

Table 1 Characteristics of current cigarette smokers versus current cigarette smokers with internet access, 2000-2002 NJATS

\begin{tabular}{|c|c|c|}
\hline & $\begin{array}{l}\text { Current } \\
\text { smokers } \\
(n=3477)^{*}\end{array}$ & $\begin{array}{l}\text { Current smokers } \\
\text { with internet } \\
\text { access }(n=2399)^{*}\end{array}$ \\
\hline Age, mean $( \pm S D)$ & $41.6(0.31)$ & $38.2(0.33)$ \\
\hline Male & $54.0(2.1)$ & $52.8(2.6)$ \\
\hline White & $73.4(2.0)$ & $79.9(2.2)$ \\
\hline \multicolumn{3}{|l|}{ Education } \\
\hline High school education or less & $55.7(2.1)$ & $46.4(2.6)$ \\
\hline Some college & $31.0(2.0)$ & $36.3(2.6)$ \\
\hline College degree or more & $13.3(1.3)$ & $17.2(1.7)$ \\
\hline Cigarettes per day, mean $( \pm S D)$ & $15.1(0.25)$ & $14.4(0.28)$ \\
\hline First cigarette $\leqslant 30$ min after waking & $45.3(2.2)$ & $41.3(2.6)$ \\
\hline Made a quit attempt in past 12 months & $54.2(2.1)$ & $56.0(2.6)$ \\
\hline \multicolumn{3}{|c|}{$\begin{array}{l}\text { Data are presented in percentages }( \pm 95 \% \mathrm{Cl}) \text { based on weighted data, } \\
\text { unless stated otherwise. } \\
\text { *Unweighted } n \text {. }\end{array}$} \\
\hline
\end{tabular}


Table 2 Prevalence of internet cigarette purchasing among all current cigarette smokers and current cigarette smokers with internet access, 2000-2002 NJATS

\begin{tabular}{|c|c|c|c|c|}
\hline & \multicolumn{2}{|c|}{$\begin{array}{l}\text { Current smokers } \\
(\mathrm{n}=3447)^{*}\end{array}$} & \multicolumn{2}{|c|}{$\begin{array}{l}\text { Current smokers with } \\
\text { internet access }(n=2399)^{*}\end{array}$} \\
\hline & $\begin{array}{l}\text { Ever } \\
\text { purchased }\end{array}$ & $\begin{array}{l}\text { Usually } \\
\text { purchase }\end{array}$ & $\begin{array}{l}\text { Ever } \\
\text { purchased }\end{array}$ & $\begin{array}{l}\text { Usually } \\
\text { purchase }\end{array}$ \\
\hline 2000 & $1.1(0.7)$ & $0.8(0.6)$ & $1.7(1.0)$ & $1.1(0.9)$ \\
\hline 2001 & $1.7(0.8)$ & $0.5(0.4)$ & $2.7(1.2)$ & $0.8(0.6)$ \\
\hline 2002 & $6.7(2.0)$ & $3.1(1.6)$ & $10.0(2.9)$ & $3.6(1.6)$ \\
\hline Overall & $2.9(0.7)$ & $1.3(0.5)$ & $4.5(2.4)$ & $1.7(0.6)$ \\
\hline
\end{tabular}

Data are presented in percentages $( \pm 95 \% \mathrm{Cl})$ based on weighted data. *Unweighted $\mathrm{n}$.

year had greater odds of ever purchasing cigarettes via the internet than smokers who attempted to quit in the past year. Additionally, there were significant differences by year, with current cigarette smokers in 2002 being more likely than smokers in 2000 to report ever purchasing tobacco via the internet.

We also examined the prevalence of usually buying cigarettes via the internet by demographic characteristics and tobacco use behaviour (table 3 ). Trends in the rates of usually buying via the internet were largely similar to the trends seen in rates of ever purchasing via the internet. After adjusting for all other factors, significant associations were found by age and time to first cigarette. Current cigarette smokers aged 45-64 years had a greater likelihood of indicating internet as their usual source of cigarettes relative to younger age groups. Smokers who reported smoking their first cigarette within 30 minutes of waking had greater odds of usually purchasing cigarettes via the internet than those who began smoking later in the day. Also, in 2002, smokers were more likely to report internet as their usual source for cigarettes than smokers in 2000.

\section{DISCUSSION}

To our knowledge, this is the first population based study of adults to examine internet cigarette purchasing in repeated surveys and identify characteristics associated with internet cigarette purchasing. Our findings indicate that internet cigarette purchasing among New Jersey smokers is growing. From 2000 to 2002, the prevalence of ever purchasing tobacco via the internet among adult cigarette smokers increased by over $500 \%$ and usually purchasing cigarettes via the internet increased by nearly $300 \%$. The sharp rise in internet cigarette purchasing among New Jersey smokers in 2002 is likely attributed in large part to the state's cigarette excise tax increase of that same year. The growth of internet cigarette purchasing also corresponds, as expected, with the well documented growth of websites selling cigarettes. Moreover, we suspect that internet cigarette vendors have capitalised on rising cigarette prices by increasing marketing and promotional efforts that target smokers with messages of tax-free or discount prices.

Not surprisingly, our study found that the smokers most likely to turn to the internet for cheaper cigarettes were those who consumed the largest quantities of tobacco-they are

Table 3 Prevalence and adjusted odds ratio (OR) of internet cigarette purchasing among current cigarette smokers with internet access $(n=2399)^{*}, 2000-2002$ NJATS

\begin{tabular}{|c|c|c|c|c|c|c|}
\hline & \multicolumn{3}{|l|}{ Ever purchased } & \multicolumn{3}{|c|}{ Usually purchased } \\
\hline & \multirow[b]{2}{*}{$\%( \pm 95 \% \mathrm{Cl})$} & \multicolumn{2}{|c|}{ Adjusted OR† } & \multirow[b]{2}{*}{$\%( \pm 95 \% \mathrm{Cl})$} & \multicolumn{2}{|c|}{ Adjusted ORT } \\
\hline & & $\overline{\mathrm{OR}}$ & $(95 \% \mathrm{Cl}) \ddagger$ & & $\overline{\mathrm{OR}}$ & $(95 \% \mathrm{Cl}) \ddagger$ \\
\hline \multicolumn{7}{|l|}{ Sex } \\
\hline Male & $4.3(2.5)$ & 1.0 & Referent & $1.1(0.7)$ & 1.0 & Referent \\
\hline Female & $4.7(2.8)$ & 1.1 & (0.7 to 1.8 ) & $2.5(1.0)$ & 2.0 & $(0.9$ to 4.6$)$ \\
\hline \multicolumn{7}{|l|}{ Race/ethnicity } \\
\hline White & $4.9(2.7)$ & 1.0 & Referent & $2.0(0.7)$ & 1.0 & Referent \\
\hline Black & $1.8(1.7)$ & 0.4 & (0.1 to 1.3 ) & $1.0(1.5)$ & 0.5 & $(0.1$ to 2.5$)$ \\
\hline Hispanic & $3.6(2.0)$ & 0.9 & $(0.3$ to 2.5$)$ & $1.0(1.4)$ & 0.9 & $(0.2$ to 4.5$)$ \\
\hline Other & $5.7(5.4)$ & 1.3 & $(0.4$ to 4.2$)$ & $0.0(0.0)$ & 0.0 & $(0.0$ to 0.0$)$ \\
\hline \multicolumn{7}{|l|}{ Age (years) } \\
\hline $18-24$ & $4.1(2.6)$ & 1.0 & Referent & $0.7(0.8)$ & 1.0 & Referent \\
\hline $25-44$ & $3.1(2.4)$ & 0.6 & (0.3 to 1.2 ) & $0.8(0.5)$ & 1.1 & (0.3 to 4.3 ) \\
\hline $45-64$ & $7.2(3.5)$ & 1.1 & $(0.3$ to 2.5$)$ & $4.0(1.8)$ & 4.4 & (1.1 to 17.1 ) \\
\hline $65+$ & $6.4(5.6)$ & 0.9 & $(0.2$ to 3.3$)$ & $2.7(3.7)$ & 2.9 & $(0.4$ to 19.3$)$ \\
\hline \multicolumn{7}{|l|}{ Education } \\
\hline High school or less & $3.8(1.5)$ & 0.6 & Referent & $1.7(0.9)$ & 1.3 & Referent \\
\hline Some college & $4.8(1.9)$ & 1.3 & (0.7 to 2.4 ) & $1.9(1.1)$ & 1.4 & (0.6 to 3.2$)$ \\
\hline College degree or more & $5.8(2.2)$ & 1.6 & $(0.9$ to 3.0$)$ & $1.4(1.2)$ & 0.6 & $(0.2$ to 1.8$)$ \\
\hline \multicolumn{7}{|l|}{ Cigareftes per day } \\
\hline$\leqslant 10$ & $3.3(1.3)$ & 1.0 & Referent & $1.3(0.8)$ & 1.0 & Referent \\
\hline $11-20$ & $4.5(1.6)$ & 1.2 & (0.6 to 2.4 ) & $1.8(1.0)$ & 0.6 & (0.2 to 1.8$)$ \\
\hline $21-30$ & $4.7(3.6)$ & 1.1 & $(0.4$ to 3.5$)$ & $3.0(3.0)$ & 0.7 & $(0.2$ to 3.0$)$ \\
\hline$\geqslant 31$ & $14.4(7.8)$ & 3.9 & (1.5 to 10.2 ) & $3.4(3.1)$ & 1.0 & $(0.2$ to 3.9$)$ \\
\hline \multicolumn{7}{|l|}{ Time to first cigarette } \\
\hline$\leqslant 30$ mins after waking & $6.2(2.8)$ & 1.4 & $(0.7$ to 2.6$)$ & $3.1(1.3)$ & 3.3 & (1.2 to 9.2 ) \\
\hline $30+$ mins after waking & $3.4(2.4)$ & 1.0 & Referent & $0.8(0.6)$ & 1.0 & Referent \\
\hline \multicolumn{7}{|l|}{ Past year quit attempt } \\
\hline Yes & $3.3(2.0)$ & 1.0 & Referent & $1.1(0.7)$ & 1.0 & Referent \\
\hline No & $6.0(3.0)$ & 1.8 & $(1.1$ to 3.0$)$ & $2.5(1.1)$ & 1.8 & (0.9 to 4.2$)$ \\
\hline \multicolumn{7}{|l|}{ Year } \\
\hline 2000 & $1.7(1.0)$ & 1.0 & Referent & $1.1(0.9)$ & 1.0 & Referent \\
\hline 2001 & $2.7(1.2)$ & 1.6 & (0.7 to 3.4$)$ & $0.8(0.6)$ & 0.6 & $(0.2$ to 1.6$)$ \\
\hline 2002 & $10.0(2.9)$ & 6.4 & (3.0 to 13.4 ) & $3.6(1.6)$ & 2.9 & (1.1 to 7.7$)$ \\
\hline Overall & $4.5(2.4)$ & & & $1.7(0.6)$ & & \\
\hline
\end{tabular}


older, smoke more cigarettes per day, have higher tobacco dependence, and are not serious about quitting. Heavier smokers and those without a past year quit attempt were more likely to have ever purchased cigarettes via the internet. Older smokers (aged 45-64 years) and smokers with a shorter time to their first cigarette in the morning were more likely to report the internet as their usual source for cigarettes. These hard core smokers, characterised as older, heavier, more dependent smokers, understandably spend more money on cigarettes, and thus have a strong economic incentive to buy cigarettes at a lower cost. Indeed, the online tobacco industry claims the average buyer of online tobacco is a 52 year old woman. ${ }^{21}$ Our results were also consistent with the study of smokers in New York, ${ }^{19}$ which found that those who smoked more cigarettes per day were more likely to seek cigarettes from cheaper sources, including the internet.

Our study has several limitations to consider. First, the percentage of adults using the internet was consistently higher in New Jersey than the nationwide average. ${ }^{22}$ Also, for several years New Jersey has had one of the highest cigarette excise tax rates in the nation. For these reasons, the rate of internet cigarette purchasing may be higher among New Jersey smokers than in states where fewer smokers are using the internet or where the retail price of cigarettes is low. Alternatively, New Jersey's close proximity to other states with lower cigarette excise taxes could moderate the impact of the internet for cigarette purchasing. In any case, we would caution against generalising these results beyond current smokers who reside in New Jersey. Second, our data rely on self report and thus we are not able to determine the extent of under- or over-reporting. Third, the survey question addressing internet access was changed in 2002. Although rates of reported internet access were similar across years, differences in wording could affect survey estimates. Fourth, response rates for the NJATS were low. In recent years, similar RDD surveys conducted in New Jersey have had low response rates consistent with the NJATS, such as NJBRFSS (28.8\% in 2000 and $34 \%$ in 2001). ${ }^{23}$ Rates of internet cigarette purchasing might differ among respondents and non-respondents. Lastly, this study was not able to address the larger question of whether the presence of cheaper cigarettes on the internet decreased cessation rates. Our study examined the only available measure of quitting that was consistent across all three years of the NJATS-past year quit attempt—which did not assess a smoker's intention to quit in the future.

While the details of this study are most germane to New Jersey, the implications are national. The growth of internet tobacco sales threatens to offset the impact of increased cigarette excise taxes and other tobacco control efforts intended to reduce smoking prevalence and consumption. The availability of low cost cigarettes via the internet diminishes external motivations to quit. Instead of being priced out by large increases in cigarette excise tax, the internet offers heavy smokers relatively easy access to vendors that offer cigarettes far below the retail price in many states. Indeed, Hyland, et al ${ }^{19}$ found intent to purchase cigarettes over the internet in the next year was twice as high as past 12 month internet purchase. And while the majority of smokers usually buy their cigarettes by the pack, ${ }^{18}$ nearly all internet cigarette vendors require at least a minimum purchase of one carton. $^{2}$ As suggested by Emery and colleagues, places with high concentrations of heavy smokers who routinely buy cigarettes by the carton are likely to see higher rates of internet cigarette purchasing. ${ }^{18}$ And indeed, our results suggest that heavy, more dependent smokers who are less interested in quitting have discovered the internet as their source for cheaper cigarettes. Beyond cost savings, we would also suggest that these websites offer positive
What this paper adds

Only one published study has examined adult internet cigarette purchasing. Since that study, there has been a proliferation of internet cigarette vendors and over two thirds of US states have increased their cigarette excise taxes. The existing literature also lacks any demographic profile of adult internet tobacco purchasers.

We found that the prevalence of ever purchasing tobacco via the internet increased between 2000 and 2002 by over $500 \%$, and usually purchasing increased by nearly $300 \%$ among adult cigarette smokers in New Jersey. Internet purchasing was most common among heavier and more dependent smokers. Monitoring of internet cigarette purchasing patterns is needed to understand all the factors that can influence smoking cessation and prevalence.

reinforcement for smoking, a safe haven for smokers in the face of mounting social pressures to quit. The website dirtcheapcig.com even promotes itself as "the last refuge of the persecuted smoker".

To discourage the widespread availability of non- or lowertaxed sources of cigarettes, the state and federal government should devote more resources to identifying internet cigarette vendors and enforcing the Jenkins Act. Some states, including New Jersey, have attempted to collect back taxes from residents who purchased cigarettes via the internet. ${ }^{12} 25$ However, many internet cigarette vendors remain noncompliant; in the last five years, New Jersey has collected less than $\$ 700000$ in taxes based on reports from vendors. ${ }^{25}$ Even based on conservative calculations, lost tax revenue from online cigarette sales easily amounts to millions of dollars annually for New Jersey and other states with similarly high cigarette excise taxes. As currently drafted, the Jenkins Act leaves states with limited power to sue internet cigarette vendors for non-compliance.

At least two states, Massachusetts and Washington, have filed lawsuits against internet cigarette vendors arguing that the Jenkins Act requires them to turn over the names and addresses of customers to whom it ships cigarettes. ${ }^{26}$ The outcome of these lawsuits has yet to be determined.

Federal legislation has been introduced that would strengthen the Jenkins Act and provide states with the tools to effectively enforce this law. Two bills recently passed both the US House and Senate, the internet Tobacco Sales Enforcement Act (HR 2824) ${ }^{27}$ and the Prevent All Cigarette Trafficking Act (or PACT Act, S 1177)..$^{28}$ The bills have similar provisions that would require internet cigarette vendors to register with states to which they sell and comply with all state tobacco tax laws as if the vendor were based in the state. As currently written, these bills would severely restrict internet tobacco sales but not ban these sales. The US House and Senate must now agree upon joint legislation. Several states have already prohibited or restricted internet cigarette sales including New York, Alaska, Maine, and California. Additionally, a bill was proposed in New Jersey (S 693) during the 2003-2004 legislative session, modelled after the New York State law, that would have prohibited internet or mail order cigarette sales directly to New Jersey consumers, but there was no subsequent legislative action. ${ }^{29}$

State officials and tobacco control practitioners should educate consumers, many of whom we suspect are not aware of their tax obligation, about the legality of purchasing cigarettes from out-of-state sources. For laws to reduce tax evasion effectively, smokers must know they exist and believe the laws are consistently enforced. Smokers should be made aware that internet cigarette vendors are legally 
bound to report cigarette sales to state tax officials and that the buyer is liable for taxes if the vendor did not collect taxes at the time of purchase. The threat of state and local tax enforcement may be a strong deterrent for many smokers.

Additionally, the emergence of the internet as a source for cigarettes points strongly to the need for better state and national surveillance of adult cigarette purchasing patterns. Internet purchasers may represent a group that is more resistant to cessation or alternatively the internet may contribute to environmental norms that challenge quitting. Monitoring trends in tax avoidance behaviours will help us to understand all the factors that influence cessation and prevalence. While earlier research has shown that increasing the price of cigarettes reduces adult smoking prevalence, ${ }^{30}$ the growing popularity of internet sales may weaken the role of cigarette tax increases. Future economic studies should consider tax avoidance behaviours, particularly internet purchasing, when examining the effect of tax increases on smoking prevalence.

\section{ACKNOWLEDGEMENTS}

Completion of this work was financially supported in part by a contract from the New Jersey Department of Health and Senior Services (NJDHSS), through funding from the Master Settlement Agreement and New Jersey's cigarette excise tax. The interpretations of data, and conclusions expressed in this manuscript, are those of the authors and do not necessarily represent the views of NJDHSS.

\section{Authors' affiliations}

M Hrywna, C D Delnevo, D Staniewska, University of Medicine \& Dentistry of New Jersey, School of Public Health, New Brunswick, New Jersey, USA

\section{REFERENCES}

1 Streitfeld D. Online tobacco sales ignited fight over taxes. The Washington Post 29 August 2000:1-20.

2 RibisI KM, Kim AE, Williams RS. Web sites selling cigarettes: how many are there in the USA and what are their sales practices? Tobacco Control $2001 ; 10: 352-9$.

3 Ribisl KM. The potential of the internet as a medium to encourage and discourage youth tobacco use. Tobacco Control 2003;12(suppl I):i48-59.

4 Weinberg A. Philip Morris Tries to Smoke the Web. Forbes.com[online]. Sept 23, 2002. Available at: http://www.forbes.com/2002/09/23/ 0923cigarettes.html [Accessed Nov 13, 2003].

5 Campaign for Tobacco-Free Kids. Special report: internet tobacco sales, 2003. Available at: http://tobaccofreekids.org/reports/internet/ [Accessed Nov 13, 2003].

6 Rubin R, Charron C, Dorsey M. Online tobacco sales grow, states lose. Cambridge, Massachusetts: Forrester Research Inc, 2001.
7 National Association of Convenience Stores. Remote sales of cigarettes a growing problem. Available at: www.nacsonline.com/NACS/Resource/ PRToolkit/Campaigns/prtk_rs_growing_problem.html [Accessed March 5, 2004].

8 Lindblom E. State cigarette tax increases since January 1, 2002. Washington DC: Campaign for Tobacco-Free Kids, 2003

$9 \mathrm{Kim}$ AE. How internet cigarette vendors promote cheaper and tax-free cigarettes online. Poster presented at: National Conference on Tobacco or Health; San Francisco, California: November 20, 2002

10 Hodge FS, Geishirt Cantrell BA, Struthers R, et al. American Indian internet cigarette sales: another avenue for selling tobacco products. Am J Public Health 2004;94:260-1.

11 Jenkins Act. U.S. Code, Title 15 (Commerce and Trade), Chapter 10A (Collection of state cigarette taxes) Sections 375-8.

12 US General Accounting Office. Internet cigarette sales: giving ATF investigative authority may improve reporting and enforcement. Washington DC: US General Accounting Office, 2002.

13 Bryant JA, Cody MJ, Murphy ST. Online sales: profit without question. Tobacco Control 2002;11:226-7.

14 Ribisl KM, Kim AE, Williams RS. Are the sales practices of internet cigarette vendors good enough to prevent sales to minors? Am J Public Health 2002;92:940-1.

15 Ribisl KM, Williams RS, Kim AE. Internet sales of cigarettes to minors. JAMA 2003;290:1356-9.

16 Unger JB, Rohrbach LA, Ribisl KM. Are adolescents attempting to buy cigarettes on the internet? Tobacco Control 2001;10:360-3.

17 Abrams SM, Hyland A, Cummings KM. Internet cigarette purchasing among ninth-grade students in Western New York. Prev Med 2003;36:731-3.

18 Emery S, White MM, Gilpin EA, et al. Was there significant tax evasion after the 199950 cent per pack cigarette tax increase in California? Tobacco Control 2002;11:130-4.

19 Hyland A. Adult cigarette purchasing patterns and cigarette prices. Paper presented at: National Conference on Tobacco or Health; San Francisco, California: November 212002.

20 Research Triangle Institute. SUDAAN User's Manual, Release 8.0. Research Triangle Park, North Carolina: Research Triangle Institute, 2001.

21 Peters A. Online cigarettes offer relief from higher taxes. The Macon Telegraph 5 October 2003. Available at: http://www.macon.com/mld/ macon/news/6941886.htm [Accessed Nov 6, 2003].

22 US Department of Commerce. A nation online: How Americans are expanding their use of the Internet. Washington DC: US Department of Commerce, 2002.

23 Centers for Disease Control and Prevention. 2000 behavioral risk factor surveillance system summary data quality report. CDC, 2001.

24 Centers for Disease Control and Prevention. 2001 behavioral risk factor surveillance system summary data quality report. CDC, 2002.

25 Colker D. Will smoke cloud state's tax vision?; officials find it difficult to collect levies on good sold online, if cigarettes are any guide. The Los Angeles Times 1 March 2003:C1.

26 Mohl B. Internet cigarette retailers targeted. The Boston Globe 17 February 2004: $\mathrm{Cl}$.

27 HR 2824. Internet Tobacco Sales Enforcement Act. $108^{\text {th }}$ Cong, $1^{\text {st }}$ Sess (2003)

28 S 1177 . Prevent All Cigarette Trafficking Act. 108 $8^{\text {th }}$ Cong, $1^{\text {st }}$ Sess (2003).

29 S 693. Prohibits Internet and mail-order cigarette sales. State of New Jersey, $211^{\text {th }}$ Legislature (2004)

30 Chaloupka FJ, Warner KE. The economics of smoking. NBER Working Paper No. W7047. Cambridge, Massachusetts: National Bureau of Economic Research, 1999. 